\title{
DIÁLOGO COM A CULTURA SURDA E A INCLUSÃO NO ENSINO SUPERIOR: AVALIAÇÃO E PROPOSIÇÃO
}

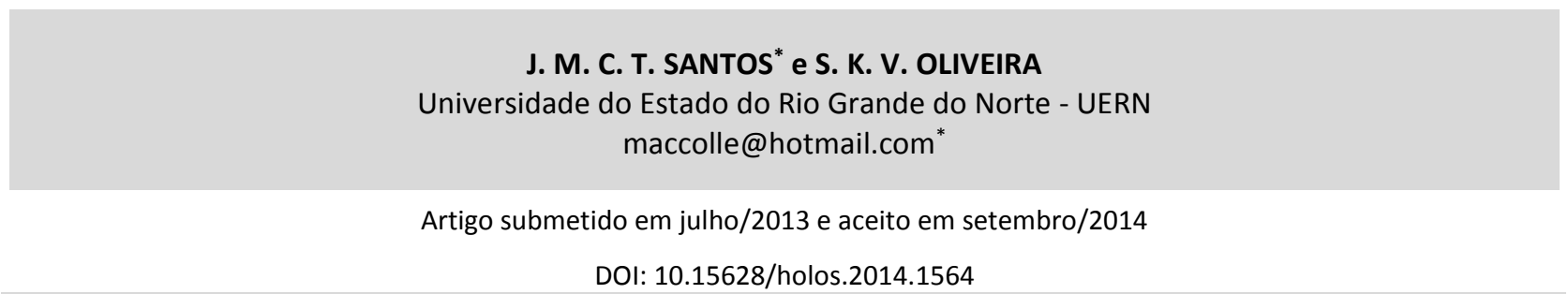

\section{RESUMO}

Este artigo analisa a inclusão no ensino superior de alunos com surdez através do acompanhamento do acesso e do desempenho escolar de três alunos do curso de Pedagogia da UERN. Tomamos como premissa teórica o campo da educação popular, em sua prática dialógica, na qual percebe a educação como direitos de todos e só realizável numa educação que possibilite a construção de saberes significativos aos aprendentes. No caminho, historiamos a forma de acesso à universidade, fizemos a leitura crítica do edital do processo seletivo e buscamos entender o cotidiano escolar dos alunos surdos e as adaptações do curso para atender suas especificidades. Essas análises foram baseadas na aplicação de questionários estruturados, aberto e fechado. Consideramos a necessidade de continuarmos construindo espaços de inclusão, de dialogicidade, seguido cotidianamente, não aceitando o acesso como referência única e percebendo que ainda estamos longe de atingirmos o "fazer parte" cidadão, como defendeu Paulo Freire.

PALAVRAS-CHAVE: diálogo; aluno surdo; educação inclusiva.

\section{DIALOGUE WITH THE DEAF CULTURE AND INCLUSION IN UNIVERSITY EDUCATION: EVALUATION AND PROPOSAL}

\begin{abstract}
This article examines the inclusion in university education of students with hearing loss through monitoring of access and academic performance of three students of Pedagogy of UERN. We take as the theoretical premise field of popular education in their practice of dialogue, which sees education as the rights of all and only achievable in an education that enables the construction of significant knowledge for learners. On the way, we count the history of the access form to university, did a
\end{abstract}

critical reading of the announcement of the selection process and seek to understand the daily school of deaf students and the adjustments to the course to meet their specific requirements. Analyses were based on structured questionnaires, open and closed. Consider the need to continue building opportunities for inclusion, dialogue, followed daily, refusing access as a reference only, and realizing that we are still far from achieving the "make part" citizen, as advocated by Paulo Freire.

KEYWORDS: dialogue; deaf students; inclusive education. 


\section{INTRODUÇÃO}

A legislação brasileira, especificamente a Constituição Federal, 1988, e as Leis de Diretrizes e Bases da Educação Nacional (LDB 9394/96), preveem a integração do educando com necessidades especiais no sistema regular de ensino. Segundo CARVALHO (2004), a construção de um sistema educacional inclusivo exige repensar o que seja a educação inclusiva, voltando para o enfoque dado ao tema após os encontros internacionais dos anos noventa. Tratam-se da Conferência Mundial de Educação para Todos, realizada em Jomtien, na Tailândia, em 1990, e da Conferência Mundial de Educação Especial, de 1994, em Salamanca, na Espanha, originando a Declaração de Salamanca. Como apresenta a autora, o novo enfoque da inclusão nos sistemas educacionais percebe a urgência de reformular as escolas para o atendimento às condições necessárias de aprendizagem para todos os sujeitos e não somente para os deficientes.

O desafio é construir e pôr em prática no ambiente escolar uma pedagogia que consiga ser comum ou válida para todos os alunos da classe escolar, porém capaz de atender aos alunos cujas situações pessoais e características de aprendizagem correspondentes requeiram uma pedagogia diferenciada (BEYER apud CARVALHO, 2004, p.23).

Desse modo, o combate é por uma escola diferenciada, democrática e cidadã, onde os indivíduos, com suas diversas virtudes, possibilidades e limitações possam encontrar subsídios para construir seu aprendizado, interagindo com os outros e com as condições acadêmicas disponíveis. O resultado da experiência inclusiva será o crescimento coletivo, com respeito mútuo e com dignidade aos envolvidos no processo.

Tomado por tal perspectiva, este trabalho analisa as possibilidades de inclusão no ensino superior de alunos com surdez através do acompanhamento do acesso e do desempenho escolar de três alunos do curso de Pedagogia da Universidade do Estado do Rio Grande do Norte (UERN).

Como premissa teórica, situa-se no campo da educação popular, em sua prática dialógica, na qual percebe a educação como direito de todos, entendendo, como FREIRE (1993), que para esse direito ser realizado não basta o consentimento para o "fazer-se presente". É necessário, além disso, a superação da educação bancária, repetidora de conhecimentos alheios aos sujeitos e a vinda da educação dialógica, possibilitadora da construção de saberes significativos aos aprendentes.

Na metodologia, primeiro, são apresentados os princípios básicos da educação inclusiva de pessoas surdas através da leitura das normas em vigor pelo Instituto Nacional de Educação de Surdos (INES). Segundo, é discutida a forma de acesso à universidade mostrando as condições, durante o processo seletivo, para que os alunos surdos tenham seus direitos respeitados estabelecendo diálogos com FERREIRA (2006), CRUZ e DIAS (2009) e CARVALHO (2004), autores que discutem os limites e as possibilidades da educação inclusiva. Por fim, o cotidiano escolar dos alunos surdos e os processos de adaptação (ou não adaptação) e do curso de pedagogia são visitados através da "voz" dos surdos. Para este fim, a aplicação de questionários estruturados, aberto e fechado, buscou entender o sentimento de inclusão, a capacidade de adquirir as habilidades exigidas ao nível superior, as condições estruturais do curso para atender acadêmicos com a deficiência auditiva e a relação com os professores e alunos ouvintes. 


\title{
2 SEGUINDO AS NORMAS
}

O Instituto Nacional de Educação de Surdos (INES), órgão do Ministério da Educação (MEC), com sede no Rio de Janeiro, apresenta-se como um centro nacional de referência na área da surdez. O Instituto, fundado no século XIX, durante o segundo reinado, como asilo para abrigar pessoas surdas, muitas delas abandonadas pela família, assume como sua a tarefa de fomentar a integração, lembrando que esta deve "ser um processo individual, fazendo-se necessário estabelecer, para cada caso, o momento oportuno para que o educando comece a frequentar a classe comum, com possibilidade de êxito e progresso". O caminho histórico percorrido pelo INES foi diverso e contraditório vindo, a partir de 1993, a adquirir a atual personalidade, passando a ser o virtuoso centro nacional de referência na área da surdez. Dessa forma, o Instituto Nacional de Educação de Surdos - INES, "tem como missão institucional a produção, o desenvolvimento e a divulgação de conhecimentos científicos e tecnológicos na área da surdez em todo o território nacional", subsidiando a política nacional de educação, na perspectiva de promover e assegurar o desenvolvimento global da pessoa surda, sua plena socialização e o respeito as suas diferenças (www.ines.gov.br) ${ }^{1}$.

Não deixa de ser interessante pensar que um órgão criado para excluir, livrando (ou escondendo) da sociedade os indesejáveis, venha a se transformar em um órgão que vai trabalhar pela integração. No entanto, é exatamente sua história, os erros e acertos conseguidos, que fazem pensar quais os passos necessários e possíveis na inclusão de pessoas surdas. Para discutir a inclusão de aluno surdo no ensino superior, tomando como base a perspectiva dialógica, em Paulo Freire, vale apresentar as posições do INES, divulgadas através do texto intitulado: "Integração escolar do aluno surdo" (www.ines.gov.br).

Assim, centrar na ideia de que:

\begin{abstract}
A integração do aluno surdo em classe comum não acontece como num passe de mágica. É uma conquista que tem que ser feita com muito estudo, trabalho e dedicação de todas as pessoas envolvidas no processo: aluno surdo, família, professores, fonoaudiólogos, psicólogos, assistentes sociais, alunos ouvintes, demais elementos da escola (www.ines.gov.br).
\end{abstract}

Não basta, então, boa vontade, interesse, dedicação de alguns. É um processo que envolve diversas instituições, governos, leis, profissões, comunidade e os próprios sujeitos.

Obstante, a inclusão de alunos surdos nas escolas regulares, em diversos níveis de ensino, já é uma realidade. Segundo o Instituto Brasileiro de Geografia e Estatística (IBGE), há no país quase seis milhões de pessoas surdas². Em 2004, segundo o Censo Escolar MEC/INEP, havia mais de sessenta mil alunos surdos ou com deficiência auditiva matriculados na Educação Básica, sendo somente próximo três mil o número deles no Ensino Médio, mostrando que apenas uma parcela pequena dos surdos que entram na escola consegue progressão. Mesmo assim, podemos considerar que em termos de Educação Básica, têm acontecido diversos tipos de iniciativa, visando não só a inclusão física, mas a permanência desses alunos nas escolas com aprendizados

\footnotetext{
${ }^{1}$ As informações retiradas do sítio do INES (www.ines.gov.br) foram acessadas em 12 de julho de 2010.

2 Os dados são do CENSO 2000.
} 
significativos para a sua vida e para a sua cultura. Não chega, infelizmente, a atingir a marca de quatro, a porcentagem de alunos que entram e concluem a educação básica.

No entanto, em relação ao ensino superior, os números são ainda mais desoladores. Os dados do Censo da Educação Superior de 2003 indicam a proximidade de 600 alunos surdos ou com deficiência auditiva matriculados em Instituições de Ensino Superior no Brasil (RAMOS, 2006). Mesmo assim, podemos pensar sobre as precauções necessárias para incluir o aluno surdo na classe regular na educação básica e, ainda mais, no ensino superior. Dessa maneira, segundo o INES, faz-se necessário: preparação de recursos humanos, adaptação e complementações de currículos, novas tecnologias de ação, pesquisas, divulgação de experiências e preparo da comunidade.

Como se pode perceber, a simples entrada no aluno surdo em uma classe regular pouco representa na política pela inclusão. Preparação de professores, formação em Língua Brasileira de Sinais (Libras), contratação de intérpretes são imprescindíveis. Adaptação, pesquisa e redimensionamento do currículo para atender o aluno são urgentes. Pensar forma de complementar o currículo com atividades direcionadas são maneiras para não excluir o 'incluído'. É necessário ainda adquirir, aprender a usar e tornar acessíveis tecnologias para facilitar o aprendizado dos conteúdos e a interdisciplinaridade. Somadas a tudo isso, pesquisas e experiências precisam ser escritas, incentivadas, relatadas dentro e fora da instituição. E por fim, mas não menos importante, o envolvimento da comunidade tornando ação da escola referendada socialmente.

A questão, entretanto, não se resume nos itens acima. O texto do INES apresenta uma questão fundamental:

Por ocasião da aprendizagem sistematizada do saber, quando do ingresso da criança no sistema de ensino, o surdo é obrigado a utilizar-se da Língua Portuguesa, um sistema lingüístico que geralmente não domina ou domina precariamente, embora um desempenho razoável na compreensão e expressão desse idioma possibilite o acesso a níveis mais elevados de escolaridade. Isto leva a deduzir que a oferta de oportunidade educacional sempre favorece a melhoria do desempenho do instrumental lingüístico dos surdos e é imprescindível para a evolução acadêmica dessas pessoas (www.ines.gov.br).

O domínio da Língua Portuguesa é uma necessidade e um obstáculo a ser superado pelo aluno surdo. Atingir níveis de estudos mais elevados, como o ensino superior, exige esse domínio. Desenvolver, desde cedo, a apreensão da Língua Portuguesa é fundamental para o futuro do surdo, mesmo que considerada como segunda língua. Para os surdos,

a Língua Portuguesa é um instrumento lingüístico que não se apresenta como recurso que vem facilitar o intercâmbio com o mundo, mas um obstáculo que precisam transpor com grande dificuldade. Por outro lado, a Libras não é código universal que possibilita tradução, mas sim, a interpretação, quando se procura estabelecer uma correspondência entre as duas línguas (idem).

Por um lado, por mais difícil que seja aprender a Língua portuguesa, levando em conta que a aquisição da linguagem se efetiva quando há condições internas do indivíduo e condições externas adequadas, ela é um obstáculo que precisa ser superado. Por outro lado, a LIBRAS nem 
sempre encontra interpretação entre as pessoas ouvintes. A distância que separa o ouvinte e o surdo aparenta intransponível.

Os surdos possuem como principal marca a questão linguística, representada pela Língua de Sinais, no caso do Brasil, a Língua Brasileira de Sinais. Essa peculiaridade tem acarretado diferentes tipos e níveis de dificuldades em consolidar um processo inclusivo com esses alunos, refletindo na continuidade de sua escolarização até ao nível universitário.

Nesse contexto, como pensar a inclusão do surdo no ensino superior? Quais as condições existentes na universidade, ou particularmente na Universidade do Estado do Rio Grande do Norte (UERN), que pode justificar o acesso do aluno surdo como um processo inclusivo? Como se dá, de fato, pela ótica do aluno surdo, a inclusão na UERN?

\section{DIÁLOGO COM A CULTURA DO SURDO}

Para responder as questões acima se faz necessário definir o campo, respondendo outra indagação: o que é a pessoa surda? Para essa resposta a própria surdez precisa ser entendida. Entender o aluno surdo exige sensibilidade para compreender o que os sons não emitem. Exige atenção para ver o significado das palavras através dos gestos, das mãos, do olhar. A expressão corporal, a intensidade dos movimentos, as expressões faciais 'falam' dentro da lógica do sujeito surdo. Nossa dificuldade de compreensão revela o distanciamento entre dois mundos e não a deficiência do outro.

Nessa perspectiva, definimos a surdez, com CRUZ e DIAS (2009),

como experiências e inter-relações visuais e os surdos como diferentes linguisticamente, bilíngues, biculturais, pertencentes a uma comunidade linguística que os apresenta como pessoas que se comunicam, interagem e se posicionam na experiência visual (p. 66).

São, assim, reconhecidos em relação à experiência visual e distantes da experiência auditiva devendo ser compreendidos como sujeitos culturais, participante de uma comunidade do olhar. Sendo entendidos como diferentes culturalmente, os surdos não são 'deficientes', são estrangeiros, de uma cultura diferente da maioria, diferente da cultura dominante, com uma tradição centrada no olhar e não no ouvir.

Desse modo, ainda com CRUZ e DIAS (2009), o surdo acessa o conhecimento através do uso comum de um código linguístico de primazia visual, "porque a sua língua é vista no corpo do outro" (p. 67). Esta comunidade tem uma língua viva, densa e completa, de fácil adaptação, com códigos, gramática, léxicos e símbolos que se renovam, composta de movimentos e "formatos específicos de mãos, braços, olhos, face, cabeça e postura corporal, que combinados fornecem as características gramaticais necessárias para a formação de uma língua" (idem, ibidem). Só através desta língua que a pessoa surda consegue alcançar as características linguísticas.

Sendo assim, a comunidade surda é uma minoria linguística e, também, cultural, já que a língua de sinais é utilizada por um grupo restrito e específicos de usuários, "que carrega em si uma cultura própria e específica, compreendida como uma diferença na multiplicidade humana" (idem, p. 68). 
Demais interessante ainda na definição de CRUZ e DIAS, para a construção de relacionar educação popular e inclusão, é quando, citando SKLIAR (1997), define a comunidade surda como "caracterizada por compartilhar uma Língua de Sinais e valores culturais, hábitos e modos de socialização próprios" (p. 68).

\begin{abstract}
Esses grupos minoritários não devem ser entendidos em relação à quantidade de pessoas a ele pertencente, mas como grupos que, ao longo do tempo, foram sendo colocados à parte do processo político-social e da vivência da cidadania. 0 termo "minoria" nunca se refere a uma medida numérica de um grupo. Às vezes, inclusive, alguns grupos representam quantitativamente uma maioria numa população determinada - os negros na África do Sul, por exemplo. Não é então o quantitativo o que demarca o território minoritário e majoritário, e sim, um certo tipo de mecanismo de poder, aquele que outorga tal condição: um mecanismo de poder que a nossa tradição tentou traduzir em termos de uma relação entre dominantes e subordinados (SKLIAR apud CRUZ e DIAS, 2009, P. 68).
\end{abstract}

Compreendida, portanto, como pertencente aos grupos minoritários, a comunidade surda pode ser comparada a outras comunidades vistas como subalternas, como "os indígenas, os negros, as mulheres, os loucos" (idem, ibidem). Estes grupos estão em estado de 'não poder' econômico, educacional, políticos, jurídico e social foram compreendidos e chamados por diversos apelidos: 'deficientes auditivos'; 'pessoas com deficiências'; 'pessoas portadoras de necessidades especiais'; 'portadores de deficiência'; ou 'portador de deficiência auditiva'. Todos estes apelidos percebem os deficientes, como incapazes.

\title{
4 A QUESTÃO DO ACESSO
}

O acesso aos cursos de graduação ofertados pela UERN, para todos os candidatos, se dá através do Processo Seletivo Vocacionado (PSV). O PSV permite que os alunos façam as provas direcionadas para a área das disciplinas que irão cursar durante sua formação. Sendo assim, para o curso de Pedagogia, o candidato precisará passar nos exames das provas de história, geografia, língua portuguesa (com literatura), língua estrangeira (inglês ou espanhol) e redação. Por não exigir disciplinas como física, química e matemática, o PSV apresenta-se como mais acessível, possibilitando ao aluno direcionar seus esforços para as disciplinas que mais the agrada, abandonando as disciplinas que considera de difícil compreensão. Outra particularidade do PSV, também válida para o conjunto dos candidatos, é a oportunidade do aluno da escola pública optar por disputar as vagas reservadas para estudantes oriundos também da escola pública, isto é, 50\% (cinquenta por cento) das vagas são ocupadas pela parcela de alunos que comprovar ter cursado todo o ensino fundamental e todo o ensino médio na escola pública. A política de cota é também um diferencial que reduz as dificuldades de acesso.

Agora, especificamente para os alunos surdos, o PSV oferece alguns auxílios instrumentais, que podem colaborar na realização das provas. Ainda durante a inscrição no PSV, atendendo o estabelecido no Artigo 5 do Decreto Federal no. 5.296, de 02 de dezembro de 2004, o candidato aponta em formulário próprio necessitar de condições especiais para realizar as provas, anexando laudo médico descritivo de sua necessidade especial.

Para o caso dos candidatos surdos, são oferecidos auxílio de intérprete/tradutor em libras, sala especial e correção diferenciada para a prova de redação. A Prova de Redação é corrigida 
considerando os aspectos semânticos e reconhecendo 'a singularidade lingüística manifestada no aspecto formal da Língua Portuguesa', de acordo com o estabelecido no Artigo 14, Inciso VI, Parágrafo 1어 do Decreto Federal n‥ 5.626, de 22 de dezembro de 2005.

Vale ressaltar que a UERN conta com um Departamento de Apoio à Inclusão (DAIN). O DAIN é o órgão que centraliza as discussões e ações relativas à inclusão na Universidade, fornecendo suporte técnico-pedagógico e disponibilizando o uso de tecnologia assistiva (equipamentos especiais, ajudas técnicas, softwares etc.) para que os alunos, professores e funcionários da instituição possam ter acesso aos conhecimentos, informações, relacionamentos e ambientes de estudo, sem o entrave das barreiras. Funcionando como órgão suplementar da Pró-Reitoria de Ensino de Graduação da UERN (PROEG), de acordo com as informações contidas no seu sítio na internet $^{3}$, o DAIN tem a finalidade de contribuir com a inclusão de jovens e adultos com necessidades educacionais especiais da UERN para que esses alunos possam ter acesso aos conhecimentos, informações, relacionamentos e ambientes de estudos.

É justamente através do DAIN que a estrutura para o atendimento das condições especiais para a realização das provas do PSV é montada, atendendo aos requisitos da lei, possibilitando as condições materiais específicas para o atendimento das necessidades especiais para os diferentes casos e situações que envolvam a inclusão.

A participação do DAIN no Processo Seletivo Vocacionado da UERN tem conquistado o aumento significativo dos estudantes com necessidades especiais com aprovação final, levando aos cursos universitários sujeitos que há bem pouco tempo eram considerados inaptos para atividades acadêmicas. Especificamente no caso dos surdos, as condições especiais pleiteadas e conseguidas pelo DAIN, com respaldo nas leis, para a realização dos exames são imprescindíveis para o resultado positivo dos três alunos que este estudo abarca. Vale, no entanto, apreciar um pouco mais os caminhos percorridos após a entrada no universo acadêmico. Como a inclusão continua a acontecer no cotidiano escolar universitário, é a questão.

\section{A QUESTÃO DA PERMANÊNCIA DO ALUNO SURDO}

Percebendo a surdez como uma possibilidade diferente de outras possibilidades, com uma cultura minoritária, reafirma-se a necessidade de estabelecer a comunicação, o diálogo, com o outro. É preciso ouvir o aluno surdo que conseguiu o acesso. Ele poderá refletir sobre as condições de sua inclusão, as possibilidades e debilidades do processo de "estar" e de "fazer parte". Com esse objetivo, foram abordados os três alunos surdos que fazem o curso de Pedagogia para responder um questionário sobre a participação deles na vida acadêmica da UERN.

Para a aplicação dos questionários com os surdos, tivemos o apoio de uma professora/intérprete de libras. Para a análise dos relatos, convencionamos as entrevistas em aluno 1, aluno 2 e aluno 3 para permitir o anonimato solicitado por um dos depoentes.

Os três surdos, jovens entre vinte e trinta anos de idade, revelam realidades distintas entre si no que se refere à formação escolar e à experiência de mundo.

${ }^{3}$ http://www.uern.br/graduacao/dain/faq.html 
O aluno 1, o mais novo dos entrevistados, desde cedo foi incentivado a desenvolver a oralidade, participou de cursos voltados para a surdez, foi acompanhado por especialistas e alfabetizadores de outros estados, realizou viagens para conhecer realidades diferentes da dele e de outros surdos, estando sempre voltado para a cultura escolar. Ele frequentou escolas especiais, conforme determinava as leis da época de sua alfabetização. Segundo ele, por isso, logo foi alfabetizado na língua portuguesa. É uma pessoa de fácil socialização, sorridente e sempre se ver cercado de amigos ouvintes. Porém, conhece muito pouco de LIBRAS. Sua comunicação é, principalmente, pela escrita e pela leitura de lábios e expressões corporais. Nesse processo, é ressaltada a importância do papel desempenhado pela família do surdo em sua socialização.

O aluno 2, apesar da aparência tímida, se apresenta como autônomo, líder entre os surdos, consciente de sua situação na sociedade, desempenhando importante papel na luta pelos direitos de pessoas surdas ou com baixa audição. Logo no início da aplicação do questionário ele se dispõe a expressar tudo que percebe ainda incorreto na UERN, mostrando insatisfação com os professores (não com todos como faz questão de pontuar várias vezes) que não compreendem sua cultura, suas diferenças e não cuidam do seu aprendizado. Faz menção também aos alunos ouvintes que não procuram dialogar com ele. Mostra ainda que não valoriza muito a cultura escrita da língua portuguesa (tem muita dificuldade com a escrita e a leitura). Prefere se comunicar em LIBRAS. Na UERN, vê-se um pouco isolado, fora das rodas, com poucos amigos. Para ele seus melhores amigos são surdos e estão fora da universidade.

O aluno 3, o mais velho do grupo, apresenta muita animação em participar da pesquisa. Domina plenamente a LIBRAS. Consegue também ler e escrever na língua portuguesa, no entanto, como faz questão de mostrar, prefere o uso de sinais. Muito curioso, faz questão de perceber se as questões anotadas estão de acordo com o que quis responder. Confere, várias vezes, com a intérprete as respostas apontadas. Diz que aprendeu o que sabe na escola especial, mas acredita ser melhor a integração. Gosta de se comunicar e fazer amizade. Mesmo assim, acha muito difícil manter relações amigáveis com pessoas ouvintes. Como o aluno 2, ele também participa da associação dos surdos do município.

No quadro abaixo, estão as principais questões apontadas nas entrevistas:

\begin{tabular}{|c|c|c|c|}
\hline $\begin{array}{l}\text { Motivos de } \\
\text { opção pelo } \\
\text { curso. }\end{array}$ & $\begin{array}{l}\qquad \text { ALUNO } 1 \\
\text { Porque oferece um amplo } \\
\text { mercado de trabalho. }\end{array}$ & $\begin{array}{l}\text { ALUNO } 2 \\
\text { Exigência da família. } \\
\text { Apoio dos amigos. }\end{array}$ & $\begin{array}{l}\text { ALUNO } 3 \\
\text { Porque oferece um amplo } \\
\text { mercado de trabalho. Por } \\
\text { influência dos amigos. }\end{array}$ \\
\hline $\begin{array}{l}\text { Como avalia } \\
\text { a estrutura } \\
\text { da } \\
\text { universidade } \\
\text { para } \\
\text { propiciar o } \\
\text { aprendizado } \\
\text { dele. }\end{array}$ & $\begin{array}{l}\text { Tem uma estrutura regular. A } \\
\text { instituição sofreu poucas } \\
\text { alterações para lhe receber. } \\
\text { Sente dificuldades em } \\
\text { permanecer no curso, por falta } \\
\text { de apoio dos professores, pela } \\
\text { falta de intérprete e pela falta } \\
\text { de apoio do DAIN de uma } \\
\text { maneira mais direta. }\end{array}$ & $\begin{array}{l}\text { Tem uma estrutura regular. } \\
\text { Aponta o intérprete como a } \\
\text { melhor parte da "estrutura". }\end{array}$ & $\begin{array}{l}\text { Tem uma boa estrutura. } \\
\text { Apresenta a intérprete como } \\
\text { a melhor parte da } \\
\text { "estrutura". }\end{array}$ \\
\hline $\begin{array}{l}\text { Relação com } \\
\text { os } \\
\text { professores. }\end{array}$ & $\begin{array}{l}\text { Tem dificuldades de } \\
\text { compreender as explicações } \\
\text { dos professores, } \\
\text { principalmente, pelo fato de }\end{array}$ & $\begin{array}{l}\text { Relação conflituosa. } \\
\text { Não entende o que os } \\
\text { professores falam. } \\
\text { Os professores não procuram } \\
\text { fazê-lo entender. Não falam }\end{array}$ & $\begin{array}{l}\text { Tem dificuldade em } \\
\text { compreender o que o } \\
\text { professor fala. } \\
\text { Poucos professores olham } \\
\text { para ele quando falam. }\end{array}$ \\
\hline
\end{tabular}


alguns deles não olharem nos

olhos ao falar.

Relação com os alunos do curso. do curso. Só consegue
Tem boa relação com os alunos aprender porque recebe apoio dos colegas.

Muito. Compreende e lê suficiente.

Muito pouco. Prefere se comunicar com a língua portuguesa (escrita).

Em parte. "alguns professores e funcionários poderiam dar maior atenção a minha realidade".

respeitados na UERN.

Quais as condições propiciadas pela UERN.

\section{Quais as} dificuldades encontradas no curso.

Como avalia a atuação do DAIN. olhando para ele. Poucos são

disponíveis e entendem a

realidade dele.

Sente falta de mais apoio por parte dos alunos ouvintes. Diz que os ouvintes não se interessam em aprender LIBRAS para ajudar na comunicação com ele. Sente-se isolado, sozinho na universidade.

Pouco. Compreende e lê pouco.

Domina muito bem.

Não. Ele acredita que as pessoas se espantam com o fato de ele estar na UERN.

A intérprete.

Falta de apoio dos demais alunos. Falta de apoio dos professores. Falta de apoio da UERN. Não consegue compreender os conteúdos.

Pouco faz pelo aluno surdo.
Poucos são disponíveis e entendem a realidade dele.

Sente falta de mais apoio por parte dos alunos ouvintes.

Médio. Compreende e lê razoavelmente.

Domina muito bem.

Sim, sente-se respeitado.

A intérprete.

Conteúdos são muito difíceis. Os alunos ajudam pouco. Os professores não dão atenção especializada.

Contribui para a permanência do aluno surdo na UERN.

Algumas comparações entre as falas dos alunos possibilitam perceber o sentimento de inclusão ou de exclusão que os rodeiam.

Vale ressaltar, primeiro, o fato de o ingresso ao ensino superior ser, sim, para todos eles, uma grande conquista, motivo de comemoração. Ao expressarem com desenvoltura sobre as condições encontradas, os direitos adquiridos, as faltas, as insuficiências do curso, os desrespeitos de alguns, as amizades de outros, a dificuldade com os conteúdos estudados, os planos para o futuro profissional, as exigências que fazem (e que continuarão fazendo), demonstram a adaptação ao ambiente de direitos que eles conquistaram.

Segundo, diretamente ligado ao item anterior, é perceptível a gana, a luta para terem os seus direitos reconhecidos. Ao invés de desanimarem com o que consideram 'desrespeitos', topam a briga para se mostrarem, denunciando, insultando, procurando aprender, exigindo a presença constante de intérprete, do olhar do professor, da conversa em LIBRAS com a sala, buscando apoio 
na família, nos amigos, nos professores mais 'próximos'. Sentem que abriram uma brecha no quadro geral de exclusão que os rodeiam e não abrirão mão de continuar ali, juntos, presentes, incomodando a academia.

Terceiro, e isso é muito forte, eles esperavam muito mais acompanhamento do que estão tendo. Mesmo sem abrirem mão do sentimento de estarem presentes, sentem-se isolados, um pouco abandonados (como ressaltou um deles), seja pelos colegas da sala, pelos professores, pelo DAIN ou pela própria universidade. $\mathrm{O}$ abandono, a falta de acompanhamento, é denunciado de diversas formas: falta de apoio, sensibilidade e do olhar dos professores, dificuldade em entender os conteúdos, pouca interação com a turma, falta de intérprete em sala de aula, falta de adaptação da linguagem acadêmica para a linguagem surda.

Em todas as falas, a maioria das questões rodeava a dificuldade em entender, a necessidade de compreensão, o desejo de aprender os conteúdos do curso. Por um lado, ver os surdos colocarem a questão da aprendizagem como central é animador. Afinal de contas, o motivo central da existência da escola é a aprendizagem discente. Que todos os professores e alunos, independentes de seus limites, sempre almejem esse fim, mesmo sem desprezar a socialização, a construção de laços de amizades, o amadurecimento intelectual também como elementos importantes na escola.

Porém, por outro lado, revela a ineficiência e incompetência da estrutura institucional para fazer aquilo a que se propõe: construir e socializar conhecimento para além das barreiras físicas e intelectuais; oportunizar condições de aprendizagens para sujeitos diversos; propiciar formação de qualidade para jovens e adultos visando a formação integral destes; preparar profissionais competentes para atuarem nas escolas públicas e privadas existentes na região.

No foco da questão está a falta de estrutura. A ausência do intérprete em grande parte das aulas aponta para a dificuldade em atender quesitos básicos no trato com o outro, o surdo. Mas a não adaptação dos conteúdos em linguajar compreensível, reclamação veemente nos três entrevistados, aproxima de zero a possibilidade de entendimentos dos conteúdos complexos do ensino superior ao aluno surdo. Nisso, a presença de um professor bilíngue (ou que pelo menos olhe para o surdo ao falar) é somente devaneio daqueles que ousam continuar a luta.

Porém, faz-se presente também a dificuldade com a língua portuguesa. A barreira da língua, numa cultura totalmente letrada, é muito grave. Vendo que dos três alunos, apenas um consegue se relacionar bem com a língua portuguesa, traz o mal estar da possibilidade de inutilidade da presença desses alunos naqueles ambientes. E, certamente, os ouvintes não serão os primeiros a sentirem o desconforto. Os surdos, como constatado nos questionários, revelam, e repetem várias vezes, sobre o sentimento de isolamento, de solidão. Sentem-se transparentes, fantasmas entre os sujeitos não surdos.

Em suma, a cultura surda - rica, do olhar, gestual, presente, minoritária, apaixonante - não está conseguindo se relacionar com a cultura majoritária - da língua, do barulho, do grito. Parte devido às sérias lacunas no investimento público em formação, tecnologias, espaços inclusivos, políticas salariais, bolsas de iniciação científica afirmativas. Mas também pelo fato de, simplesmente, mas não menos grave, não perceber o outro como sujeito de direitos. Exemplo disso, relatado pelo aluno 1, foi quando a sala assistiu a um filme sobre educação, daqueles que dão exemplos magníficos de como ser um bom 'mestre', e o professor 'esqueceu' de colocar a 
legenda para o aluno surdo acompanhar as falas dos personagens. Na sala escura da transmissão, o surdo só foi percebido no fim, depois dos aplausos aos exemplos vistos na tela.

Por enquanto, deve-se inferir que a inclusão não se realiza de fato. É verdade. Não há como se conformar somente com a presença do surdo em sala de aula. O caminho, no entanto, é de seguir, aprofundar, ousar atender as necessidades de todos, buscando os ambientes de aprendizagem para as especialidades da sala, conhecidas ou não. Perceber o surdo, em sua cultura, buscar interagir com ele, e sua cultura, é o caminho que a escola deve seguir.

O processo de inclusão, apesar dos passos firmes já dados, apenas começou. A construção da escola que atenda as especificidades, como determina a norma, as declarações bem intencionadas e as diretrizes governamentais, não se refletem na realidade. A mobilização da sociedade para garantir o direito do surdo, e de todos, ainda é palavra de ordem de alguns, principalmente daqueles que sofrem diretamente o problema, mas ainda escutados em ambientes restritos. A sensibilização de todos, não pode esperar pelos novos tempos. Precisa ser agora, já, cotidianamente.

\section{PELA ESCOLA POPULAR INCLUSIVA}

Uma das principais questões levantadas pelos alunos pesquisados diz respeito ao aprendizado dos conteúdos das disciplinas. O ensino ofertado é distante da realidade do surdo, impossibilitando o aprendizado significativo do currículo. As falas dos alunos mostram a distância existente entre uma perspectiva freireana de educação e o ensino conteudista, academicista, burocratizado, autoritário e hierárquico que domina a formação em nível superior. Como então superar a situação de exclusão do aprendizado anunciado nos relatos?

De fato, no atual formato de escola, a possibilidade da inclusão como perspectiva de acesso, permanência e aprendizado referendado socialmente não parece possível. Seu intuito é o atendimento às necessidades do mercado e não o sujeito humano a formar. A possibilidade de construção de outra escola, popular, dialógica, referendada socialmente, esta sim, é capaz de atender aos desejos inclusivos de homens e mulheres para além do mercado, para a vida, para a alegria, para a construção do belo no humano.

Em tempo, isso não significa menosprezar a aprendizagem curricular. Sem minimizar a importância dos conteúdos na escola, Paulo Freire defendia uma educação que privilegiasse os saberes populares para, a partir deles, edificar os saberes científicos. Mais uma vez, a aproximação é com a cultura surda, agora olhada a partir dos princípios da educação popular.

Assim, a defesa é pela construção de uma escola popular inclusiva ${ }^{4}$. A educação popular, aproveitando os espaços escolares formais, subverte os valores dominantes, postulando a construção de sua utopia, onde gentes, vontades e ações humanas que estão lá, ousam desafiar a lógica de reprodução da miséria. Como nos mostra SAVIANNI (1991), é viável, mesmo numa sociedade capitalista, "uma educação que não seja, necessariamente, reprodutora da situação vigente, e sim adequada aos interesses da maioria, aos interesses daquele grande contingente da sociedade brasileira, explorado pela classe dominante" (p.94). Se à sociedade capitalista interessa uma escola reprodutora da desigualdade, a educação popular, mesmo em um espaço construído

\footnotetext{
${ }^{4}$ A expressão escola pública popular foi cunhada por Moacir Gadotti como concepção de uma escola emergente, resultante da
} participação popular em diferentes níveis e formas. 
para perpetuar a exclusão, pode interferir sobre a sociedade, contribuindo para a sua própria transformação.

Sendo fiel ao sonho de formar sujeitos históricos comprometidos com a felicidade de toda a humanidade, a escola deve buscar a excelência no processo ensino-aprendizagem: oferecer ao aluno dessa escola a melhor (in)formação, a qualidade e a quantidade de saberes que historicamente foi devida aos alunos de setores minoritários da sociedade. A busca pela excelência é uma luta de obstinados.

Na discussão da excelência, no entanto, o debate da qualidade precisa ser enfrentado. Com FREIRE, pode-se desprezar a ideia cínica que relaciona a excelência ao saber cartográfico, cartesiano, cientificizado, laboratorial, positivista, conteudista, posse de uma minoria encastelada em impérios de saberes a serviço de impérios do capital. Nas palavras de Moacir Gadotti [grifos do autor]:

Para Paulo Freire, o conhecimento é construído de forma integradora e interativa. Não é algo pronto a ser apenas "apropriado" ou "socializado", como sustenta a pedagogia dos conteúdos. Por isso, essa pedagogia sustenta, até hoje, a necessidade da memorização. Conhecer é descobrir e construir e não copiar. $\mathrm{Na}$ busca do conhecimento, Paulo Freire aproxima o estético, o epistemológico e o social. Para ele é preciso reinventar um conhecimento que tenha "feições de beleza" (GADOTTI, 2006, p. 76).

A escola popular inclusiva, contra-hegemônica e interessada é uma bandeira para aglutinar as lutas pela transformação da sociedade por dentro e por fora da escola, formando sujeitos históricos, respeitando as culturas minoritárias, relacionando os saberes 'científicos' com os saberes populares e vice-versa.

Desse modo, a escola e a comunidade envolvidas compartilham ideias e valores éticos e morais partindo de concepções filosóficas e metodológicas que contemplem a preservação da dignidade humana, a busca da identidade e o exercício da cidadania permeando, assim, um viver democrático e prazeroso comprometido com a educação de qualidade para todos.

\section{REFERÊNCIAS}

1. BATISTA, Maria do Socorro Xavier. A contribuição do pensamento de Freire para a educação popular em movimentos sociais. V Colóquio Internacional Paulo Freire. Recife, 2005.

2. CARVALHO, Rosita Edler. Educação Inclusiva: com os pingos nos "is". Porto Alegre: Mediação, 2004.

3. CRUZ, José Ildon; DIAS, Tárcia Regina. Trajetória escolar do surdo no ensino superior: condições e possibilidades. Rev. Brás. Ed. Especial. Marília, jan./abril, 2009, p. 65-80. Disponível em http://www.scielo.br/scielo.php?script=S1413-65382009000100006. Acessado em 14 de julho de 2010.

4. FERREIRA, Maria Cecília Carareto. Os movimentos possíveis e necessários para que uma escola faça a inclusão de alunos com necessidades educacionais especiais. In: JESUS, D. M.; BAPTISTA, C. R.; VICTOR, S. L. (orgs.). Pesquisa e Educação Especial: mapeando produções. Vitória: Edufes, 2006, p. 139-154. 
5. FREIRE, Paulo. Pedagogia da Autonomia: saberes necessários a prática educativa. Rio de Janeiro: Paz e Terra, 2000.

6. FREIRE, Paulo. Pedagogia do Oprimido. São Paulo: Paz e Terra, 1993.

7. GADOTTI, Moacir. Escola Cidadã. São Paulo: Cortez, 2006.

8. INTEGRAÇÃO escolar do aluno surdo. Documento, INES/MEC. Disponível em www.ines.gov.br Acessado em 12 de julho de 2010.

9. RAMOS, Rossana. Passos para a inclusão. São Paulo: Cortez, 2006.

10. SAVIANI, Dermeval. Escola e Democracia. São Paulo: Cortez, 1991.

11. SKLIAR, Carlos. A Surdez: um olhar sobre as diferenças. Porto Alegre: Mediação, 1997. 